DOI: $10.33947 / 1982-3282-V 14 N 1-2-4145$

\title{
CONDIÇÕES MICROBIOLÓGICAS DO COMÉRCIO AMBULANTE DE ALIMENTOS EM GUARULHOS-SP
}

\author{
MICROBIOLOGICAL CONDITIONS OF STREET FOOD TRADE IN GUARULHOS-SP
}

\author{
Erica Ângela de Oliveira1 ${ }^{1}$ Priscila Luiza Mello²
}

Submetido: $27 / 11 / 2019$

Aprovado: 26/06/2020

\section{RESUMO}

Introdução: Vendedores ambulantes de alimentos buscam pontos estratégicos para alcançarem o maior número de consumidores, no centro do município de Guarulhos há um número elevado desses ambulantes. A maior parte desses alimentos não passam pela procedência correta de higienização. Objetivo: Avaliou-se a qualidade dos alimentos oferecidos por vendedores ambulantes situados aos arredores da Universidade Guarulhos. Materiais e métodos: Avaliaram-se cinco amostras provenientes de diferentes vendedores ambulantes. Foram feitas análises microbiológicas para estimativa do número mais provável (NMP) de coliformes totais e termotolerantes pela técnica dos tubos múltiplos e contagem de UFC de bactérias aeróbias mesófilas. Resultados: Os resultados indicaram contaminação por bactérias aeróbias mesófilas que podem ser potencialmente patogênicas, a amostra número quatro expressou um alto crescimento totalizando $30 \times 10^{6} \mathrm{UFC} / \mathrm{g}$, também foi constatada a presença de coliformes totais e fecais. Conclusão: Diante dos resultados obtidos concluiu-se que três das cinco amostras estão impróprias para o consumo humano por serem produtos considerados em condições higiênico-sanitárias insatisfatórias.

DESCRITORES: Coliformes totais; Coliformes fecais; Microbiologia; Condições higiênicas; Alimentação; Ambulantes

\begin{abstract}
Introduction: Street food vendors seek strategic points to reach the largest number of consumers, in the center of Guarulhos there is a high number of street vendors. Most of these foods do not go through the correct provenance of sanitation. Objective: We evaluated the quality of the food offered by street vendors around Guarulhos University. Materials and methods: Five samples from different street vendors were evaluated. Microbiological analyzes were performed to estimate the most probable number (MPN) of total and thermotolerant coliforms by the multiple tube technique and CFU count of aerobic mesophilic bacteria. Results: The results indicated contamination by potentially pathogenic mesophilic aerobic bacteria, sample number four expressed a high growth totaling $30 \times 10^{6} \mathrm{CFU} / \mathrm{g}$, it was also found the presence of total and fecal coliforms. Conclusion: Based on the results obtained, it was concluded that three of the five samples are unfit for human consumption as they are considered to be unsatisfactory hygienicsanitary conditions.
\end{abstract}

KEYWORDS: Total coliforms; Fecal coliforms; Microbiology; Hygienic conditions; Food; Street vendor

\footnotetext{
Bacharel em Ciências Biológicas pela Universidade Univeritas - UNG. E-mail: ericaa-oliveira@hotmail.com

2 Bióloga, Doutora em Biologia Geral e Aplicada pela Universidade Estadual Paulista Júlio de Mesquita - UNESP. Docente do Curso de Ciências Biológicas da Universidade UNG. E-mail: priscila.mello@prof.ung.br
} 


\section{INTRODUÇÃO}

A comercialização de produtos por vendedores ambulantes ocorre há muito tempo em nosso país, pois essa prática se tornou um modo de complementar a renda de muitos cidadãos. Os vendedores passaram também a comercializar alimentos, que possuem praticidade para aqueles que vivem uma rotina que de certa forma pode influenciar os horários de café da manhã, almoço e jantar, fazendo com que os mesmos procurem fontes de alimentação rápida e barata ${ }^{1,2}$.

Esses ambulantes buscam pontos estratégicos para alcançarem o maior número de clientes, locais como: universidades, escolas, hospitais, pontos de ônibus e empresas, são os mais procurados por esses vendedores pois a busca por uma refeição rápida e barata é grande, devido ao tempo escasso que essas pessoas têm por conta dos horários impostos em sua rotina de trabalho e/ou estudos ${ }^{3,4,5}$.

Para muitos consumidores a comida de rua constitui-se na maneira mais prática de alimentar-se enquanto estão fora de suas casas, principalmente pelo preço reduzido dos alimentos. Porém, os limitados hábitos de higiene da maioria dos vendedores ambulantes, a ausência de água potável e de refrigeração dos alimentos, a falta de áreas adequadas para descarte do lixo e de sanitários públicos nos locais de venda, favorecem a contaminação e deterioração dos alimentos comercializados nas ruas 6 .

A maior parte desses alimentos não passa pela procedência correta de higienização e ficam expostos durante várias horas em locais que não são propícios para o seu armazenamento, ocorrem então variações na temperatura, exposição a poeira e outros agentes que possam influenciar na sua qualidade, fazendo com que os indivíduos fiquem expostos a contrair doenças oriundas desse tipo de alimentação ${ }^{2,4}$.

No centro do munícipio de Guarulhos há um número elevado desses ambulantes, que oferecem alimentos com aparência e cheiro agradáveis, principalmente aos arredores da Universidade Guarulhos onde há um grande fluxo de pessoas. A maioria desses indivíduos consomem esses alimentos diariamente sem conhecimento prévio sobre a sua origem e a forma de preparação dos mesmos, portanto acredita-se que muitas doenças podem ser causadas pelo consumo indiscriminado desses produtos.

A microbiota de um alimento é constituída por microrganismos que foram adquiridos durante os pro- cessos de manipulação e processamento. Apesar de grande parte dos alimentos estar sujeita a várias fontes potenciais de microrganismos, é possível controlar os níveis de contaminação e manter a microbiota em um número aceitável pela legislação vigente, através de manuseio adequado?

As variações causadas por fatores extrínsecos e intrínsecos nos alimentos contribuem para o crescimento de microrganismos patogênicos, as más condições que esses alimentos são expostos possibilitam a formação de colônias ${ }^{8}$.

Pesquisadores calculam que aproximadamente 100 milhões de indivíduos, considerando-se a população de todos os países industrializados, contraem doenças decorrentes de alimentação inadequada, através do consumo de refeições e água contaminadas ${ }^{9}$. As autoridades da área de proteção dos alimentos classificam a contaminação de natureza biológica de origem microbiana como o perigo principal para a Saúde Pública ${ }^{10}$.

Acabar com o comércio informal de alimentos é impossível, posto que implicaria fatores de ordem econômica a serem contornados, além de mudança na mentalidade da população consumidora, no entanto, o seu controle pode ser melhorado ${ }^{11}$.

Uma das formas de avaliar as condições desses alimentos vendidos nas ruas por ambulantes, é a realização de análises dos alimentos obtidos utilizando microrganismos indicadores como bactérias do grupo dos coliformes fecais. A presença de coliformes fecais ou coliformes termotolerantes em alimentos indica a contaminação fecal, ou seja, de condições insatisfatórias, indicando a presença de enteropatógenos ${ }^{12,13,14}$.

O grupo dos coliformes constitui o indicador de contaminação fecal mais frequentemente utilizado, sendo empregado, há mais de cem anos, como parâmetro bacteriano, na definição de padrões para a caracterização e avaliação da qualidade de águas e alimentos ${ }^{15,12}$. Os coliformes totais são um grupo de bactérias que contem bacilos gram-negativos, aeróbios ou anaeróbios facultativos e que fermentam a lactose com produção de ácidos, aldeídos e gás a $35^{\circ} \mathrm{C}$ em $24-48$ horas. Coliformes fecais ou coliformes termotolerantes são bactérias capazes de desenvolver e/ou fermentar a lactose com produção de gás a $44^{\circ} \mathrm{C}$ em 24 horas $^{16}$.

O consumo desses alimentos contaminados pode acarretar a doenças que atingem nosso sistema gastrointestinal causando intoxicações alimentares, a má condição dos alimentos pode ter origem no seu cozimento incorreto, má higienização das mãos de quem 
manipula o alimento e o uso de matérias primas contaminadas na preparação do alimento ${ }^{3,17}$.

Considerando-se que os vendedores de rua são comerciantes que fornecem rotineiramente alimentos para a população, se faz necessário buscar meios que garantam o seu acesso à informação, visando uma melhoria na qualidade higiênico -sanitária dos alimentos. Um dos pontos importantes seria a obrigatoriedade de capacitação dos proprietários e funcionários desses serviços.

Tendo em vista os fatores citados acima, temos como objetivo avaliar a qualidade microbiológica dos alimentos comercializados por vendedores ambulantes situados no município de Guarulhos para evidenciar os riscos da ingestão dos mesmos. Submetendo as amostras de alimentos a análises microbiológicas, buscando detectar a presença de coliformes totais e termotolerantes, bem como realizar a contagem de bactérias aeróbicas mesófilas.

\section{MATERIAIS E MÉTODOS}

\subsection{Quantidade de amostras}

Avaliaram-se no total cinco amostras provenientes de diferentes vendedores ambulantes, as amostras foram coletadas no período da tarde quando os ambulantes chegam nos locais que costumam estar rotineiramente. A escolha do local levou em consideração a localização dos carrinhos e a higiene deles, foram analisadas amostras dos seguintes alimentos: milho, cachorro quente (não prensado), pipoca salgada, tapioca salgada e lanche natural de frango.

A obtenção das amostras aconteceu na forma de consumidora comum do produto, sem alertar ao ambulante que se trata de um projeto de pesquisa. Os resultados não foram divulgados para o ambulante.

Para determinar se o índice de contaminação das amostras oferece risco a saúde humana, foi levada em consideração a legislação criada pela Agência Nacional de Vigilância Sanitária (ANVISA) que determina os padrões adequados dos alimentos. ${ }^{18}$

\subsection{Coleta das amostras}

Imediatamente após a aquisição da amostra, a mesma foi transportada assepticamente sob refrigeração para o Laboratório de Microbiologia da Universidade Guarulhos, para realização das análises.

\subsection{Preparo das amostras}

Foram pesados $50 \mathrm{~g}$ de cada alimento, de forma a conter todos os ingredientes. As alíquotas de $50 \mathrm{~g}$ foram adicionadas a $450 \mathrm{~mL}$ de água peptonada $0,1 \%$ esterilizada, obtendo-se a diluição $10^{-1}$ e a partir desta foram preparadas as diluições decimais seguintes. As diluições $10^{-1}$ foram obtidas sempre triturando as alíquotas dos alimentos nos diluentes mencionados em liquidificador esterilizado. Para as demais diluições, sempre alíquotas de $10 \mathrm{~mL}$ foram adicionadas em $90 \mathrm{~mL}$ de água peptonada $0,1 \%$ esterilizada.

\subsection{Número mais provável (NMP) de coliformes to- tais e coliformes a $45^{\circ} \mathrm{C}$}

Realizaram-se análises microbiológicas para estimativa do número mais provável (NMP) de coliformes totais e termotolerantes e contagem de UFC de microrganismos aeróbicos mesófilos em placas.

O Número Mais Provável (NMP) de coliformes totais e coliformes fecais foi determinado através da técnica dos Tubos Múltiplos. A análise compreende duas fases distintas: a fase do teste presuntivo e a fase do teste confirmativo. No teste presuntivo foram utilizadas três séries de tubos de ensaio contendo tubos de Durham e Caldo Lactosado.

Foram feitas 3 séries de 5 tubos que continham Caldo Lactosado, com inóculos de $1 \mathrm{~mL}$ das diluições $10^{-1}, 10^{-2}$ e $10^{-3}$. As 3 séries de tubos foram incubadas a $37^{\circ} \mathrm{C}$ por $24-48$ horas. Após o período de incubação, os tubos que apresentaram produção de gás devido à fermentação da lactose do meio, evidenciada pela formação de bolhas no tubo de Durham, foram considerados positivos no teste presuntivo. Os tubos que após 48 horas não apresentaram nenhuma alteração nos tubos de Durham, foram considerados negativos.

Com o auxílio de alça de níquel cromo foram retiradas alíquotas dos tubos positivos e transferidas para tubos contendo Caldo Verde Brilhante Lactose Bile (CVBLB) e para tubos contendo Caldo E.coli (EC), para a confirmação de coliformes totais e de coliformes fecais $\left(45^{\circ} \mathrm{C}\right)$, respectivamente.

Os tubos contendo CVBLB e o inóculo foi incubado a $35^{\circ} \mathrm{C}$ por $24-48$ horas. Os tubos de Durham com produção de gás foram considerados positivos para coliformes totais, podendo ser de origem fecal ou não. Os tubos contendo EC foram utilizados para a detecção de coliformes de origem fecal. A temperatura e o período 
de incubação ( $45^{\circ} \mathrm{C}$ por 24 horas) impedem que outros microrganismos fermentem a lactose, desse modo, se houver produção de gás fica clara a presença de coliformes fecais.

\subsection{Contagem das Unidades Formadoras de Colônias:}

Para a avaliação da qualidade sanitária do alimento foram quantificadas as bactérias autótrofas mesófilas, segundo o crescimento das colônias no ágar Plate Count Agar (PCA).

Pela técnica de semeadura em superfície, alíquotas de $0,1 \mathrm{~mL}$ das diluições $10^{-1}, 10^{-2}$ e $10^{-3}$ foram transferidas para placas de petri contendo o meio de cultura e, em seguida, espalhadas cuidadosamente com alça de drigalski, por toda a superfície até que fossem totalmente absorvidas. A seguir, incubadas a uma temperatura de $35^{\circ} \mathrm{C}$ por 24 a 48 horas. Foram selecionadas e contadas as placas que apresentaram de 20 e 200 colônias características. O número de colônias encontrado por placa será multiplicado por 10 para se obter o número de colônias por $1 \mathrm{~mL}$ e também pelo inverso do fator de diluição, obtendo-se unidades formadoras de colônias por grama (UFC/g).

\section{RESULTADOS}

A amostra de milho apresentou crescimento nas placas -2 e -3 totalizando $8 \times 10^{3} \mathrm{UFC} / \mathrm{g}$, mas não ocorreu crescimento nos tubos de caldo lactosado e nos tubos de CV (Caldo Verde Brilhante), sendo assim a mesma não apresentou índice de contaminação por coliformes totais e fecais.

O cachorro quente (não prensado) apresentou crescimento nas placas com meio PCA totalizando $114 \times 10^{3} \mathrm{UFC} / \mathrm{g}$ e no caldo lactosado, após as leituras e contagem das unidades formadoras de colônia foram passados $1 \mathrm{ml}$ de caldo lactosado para os tubos com meio EC (E.Coli) e CV (Caldo Verde Brilhante) apresentando crescimento em ambos os meios. Concluímos então que a amostra de cachorro quente estava contaminada por coliformes totais e fecais.
Para a amostra de pipoca salgada foram realizados os mesmos procedimentos, porém não apresentou crescimento nas placas de PCA e nos tubos com caldo lactosado, logo foi descartada pois não apresentou evidências de contaminação.

A amostra de tapioca salgada apresentou crescimento nas placas com meio PCA e no caldo lactosado, devido ao crescimento elevado das unidades formadoras de colônia não foi possível realizar a contagem das UFC nas três primeiras diluições, então foram realizadas mais três diluições em novas placas e as mesmas foram armazenadas novamente na estufa para posteriormente serem realizadas as contagens totalizando então $30 \times 10^{6} \mathrm{UFC} / \mathrm{g}$.

Após as leituras, foram passados $1 \mathrm{ml}$ de caldo lactosado para os tubos com meio CV (Caldo Verde Brilhante) apresentando crescimento e formação de gás nos tubos -1 e -2. Logo foram passados $1 \mathrm{ml}$ de $\mathrm{CV}$ (Caldo Verde Brilhante) para os tubos com meio EC ( $E$. coli) os mesmos apresentaram crescimento. Concluímos então que a amostra de tapioca salgada estava contaminada por coliformes totais e fecais.

$\mathrm{O}$ lanche natural de frango apresentou crescimento nas placas com meio PCA totalizando $162 \times 10^{3}$ UFC/g e no caldo lactosado, após a leitura e contagem das unidades formadoras de colônia (UFC) foram passados $1 \mathrm{ml}$ de caldo lactosado para os tubos com meio CV (Caldo Verde Brilhante) apresentando crescimento em todos os tubos. Logo após a realização da leitura foram passados $1 \mathrm{ml}$ do meio CV (Caldo Verde Brilhante) para os tubos com meio EC (E.coli) e os mesmos apresentaram crescimento. Concluímos então que a amostra de lanche natural de frango estava contaminada por coliformes totais e fecais.

Tabela 1. Contagem de unidades formadoras de colônia (UFC) presentes nas amostras analisadas.

\begin{tabular}{cc}
\hline AMOSTRA & UFC/g \\
\hline Milho & $8 \times 10^{3} \mathrm{UFC} / \mathrm{g}$ \\
Cachorro-quente & $114 \times 10^{3} \mathrm{UFC} / \mathrm{g}$ \\
Pipoca salgada & Não houve crescimento \\
Tapioca salgada & $30 \times 10^{6} \mathrm{UFC} / \mathrm{g}$ \\
Lanche natural de frango & $162 \times 10^{3} \mathrm{UFC} / \mathrm{g}$ \\
\hline
\end{tabular}

Fonte: dados da pesquisa (julho- março 2019). 
Tabela 2. Presença ou ausência de coliformes totais e fecais nas amostras analisadas.

\begin{tabular}{lcc}
\hline AMOSTRA & $\begin{array}{c}\text { COLIFORMES } \\
\text { TOTAIS }\end{array}$ & $\begin{array}{c}\text { COLIFORMES } \\
\text { FECAIS }\end{array}$ \\
\hline Milho & $\begin{array}{c}\text { Não houve } \\
\text { crescimento }\end{array}$ & $\begin{array}{c}\text { Não houve } \\
\text { crescimento }\end{array}$ \\
Cachorro-quente & + & + \\
Pipoca salgada & Não houve & Não houve \\
crescimento & crescimento \\
Lapioca salgada & + & + \\
\hline
\end{tabular}

Fonte: dados da pesquisa (julho -março 2019).

Na tabela 1 estão expressos os números referentes a quantidade de Unidades Formadoras de Colônia (UFC) e na tabela 2 a ocorrência de crescimento de Coliformes Totais e Fecais. De acordo com os resultados obtidos podemos observar que as amostras milho, cachorro quente, tapioca salgada e lanche natural de frango apresentaram a ocorrência de Coliformes Totais e Fecais indicando assim índice de contaminação.

Na figura 1 são apresentados os valores da contagem dos coliformes totais e termotolerantes encontrados nas amostras analisadas indicando o índice de contaminação.

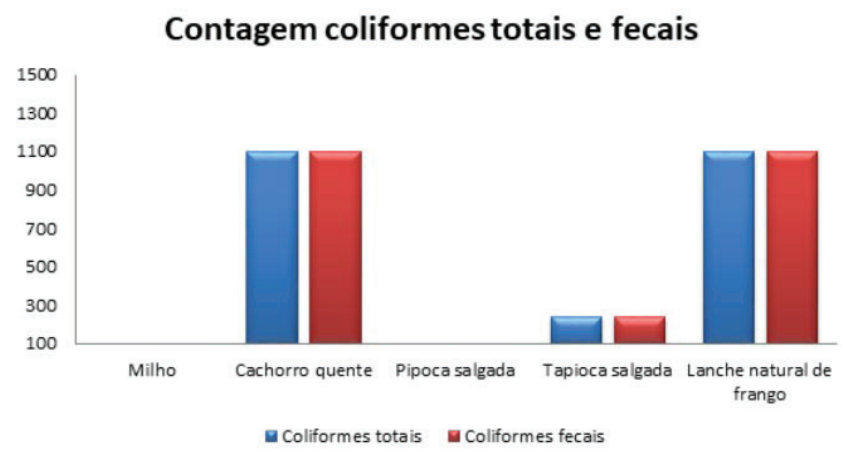

Figura 1. Contagem de coliformes totais e termotolerantes nas amostras analisadas utilizando a técnica do número mais provável.

\section{DISCUSSÃO}

De acordo com os dados coletados e baseados no regulamento definido pela Agência Nacional de Vigilância Sanitária ${ }^{18}$ a mesma determina pela resolução RDC $\mathrm{n}^{\circ} 12$ que os alimentos provenientes de restaurantes e similares tem o limite de crescimento para coliformes totais e fecais de $2 \times 10$ para alimentos à base de carnes e de $5 \times 10$ para alimentos que possuem adição de verduras e legumes temperados ou não, a partir dessas informações foi possível concluir que das cinco amostras analisadas três delas apresentaram contaminação, sendo assim as mesmas são consideradas como produtos em condições higiênico-sanitárias insatisfatórias por estarem fora dos padrões estabelecidos pela ANVISA. ${ }^{18}$

É importante ressaltar que os alimentos que indicaram contaminação elevada são aqueles que exigem maior manipulação na hora do preparo, utilizando ingredientes que passam por processo de corte e armazenamento. A tapioca salgada e o lanche natural de frango são os que apresentaram alto índice de contaminação e são esses os que contém ingredientes que são altamente manipulados pelos vendedores ambulantes durante seu preparo.

Com base nesses resultados insatisfatórios podemos ressaltar algumas possíveis razões para a contaminação nas três amostras, são elas: hábitos de higiene precários por parte dos ambulantes, irregularidades no armazenamento dos insumos, má qualidade dos insumos e locais inapropriados para a preparação desses alimentos.

É necessário salientar a importância de condições básicas de higiene para a preparação dos alimentos e cuidados com a higiene pessoal antes da manipulação dos mesmos. Destaca-se também a importância de profissionais qualificados para fiscalizar e manter as condições preconizadas pela ANVISA visando à diminuição de microrganismos que podem causar riscos à saúde da população que consome os alimentos comercializados por esses ambulantes. ${ }^{18}$

Oliveira, realizou um estudo para avaliar as condições higiênico-sanitária de ambulantes manipuladores de alimentos nos arredores do campus universitário na Universidade Federal de Goiás, foram feitas analises nas mãos de alguns ambulantes com o objetivo de avaliar o índice de contaminação por enterobactérias e os resultados obtidos indicaram que os ambulantes apresentavam níveis altos de contaminação, e então concluiu-se que o grau elevado de contaminação das mãos dos ambulantes se deve ao fato da má higienização e a manipulação de dinheiro ao mesmo tempo que ocorre a manipulação dos alimentos que servem como matéria prima. ${ }^{19}$

Souza, avaliou as condições higiênico-sanitárias dos manipuladores de alimentos em trinta pontos de comércio ambulante de alimentos na cidade de Uberaba-MG, foram realizadas análises voltadas para as condições higiênicos-sanitárias das mãos dos vendedores ambulantes e superfícies de contato com os alimentos. Foram obtidos resultados insatisfatórios indicando risco de contaminação dos alimentos. ${ }^{20}$ 


\section{CONCLUSÃO}

Após as análises concluiu-se que em um total de cinco amostras apenas duas delas não apresentaram índice de contaminação, sendo que três estavam fora dos padrões estabelecidos pela legislação considerados adequados indicando que elas estão impróprias para o consumo humano. Assim sendo, é necessário que ocorra uma reformulação nas políticas públicas que visem as questões de saúde, pois a procura por esses alimentos aumenta a cada dia.

Diante dos resultados constatou-se que são necessárias medidas para garantir a qualidade dos alimentos comercializados por ambulantes. Para isso, é fundamental que cuidados sejam tomados na hora do processamento desses alimentos visando conter a contaminação por microrganismos. Os ambulantes devem se adequar aos padrões estabelecidos pelos órgãos fiscalizadores para assegurar que os alimentos comercializados não causem risco a saúde da população. 


\section{REFERÊNCIAS}

1. Germano MIS, Germano PML, Kamei CAK, Abreu CS, Ribeiro ER, Silva KC, Lamardo LCA, Rocha MFG, Vieira VKI, Kawasaki VM. Manipuladores de alimentos: capacitar? É preciso. Regulamentar? Será preciso? Hig alimente. 2000;(14):18-22.

2. Feglo P, Sakyi K. Bacterial contamination of street vending food in Kumasi, Ghana. J Med Biomed Sci. 2012;1(1):1-8.

3. Lues JF, Rasephei MR, Venter P, Theron MM. Assessing food safety and associated food handling practices in street food vending. Int $\mathrm{J}$ Environ Health Res. 2006;16(5):319-328.

4. Muyanka C, Nayiga L, Brenda N. Nasnyama G. Practices, knowledge and risk factors of street food vendors in Uganda. Food Control. 2011;22(10):1551-1558.

5. Omemu AM, Aderoju ST. Food safety knowledge and practices of street food vendors in the city of Abeokuta, Nigeria. Food Control. 2008;19(4):396-402.

6. Balbani APS, Ossamu B. Contaminação biológica de alimentos, São Paulo, 2001. 1988. p. 83-102.

7. Lima AWO, Sousa CP. Infecções e intoxicações alimentares. In: Aspectos da ciência e tecnologia de alimentos. 1 ed. João Pessoa, PB: Nova Idéia. 2002. v. 1. p. 175-199.

8. Pinto ADM. Doenças de Origem Microbiana Transmitidas pelos Alimentos. 1996.

9. Figueiredo RM. Higiene dos alimentos. Como não comer fungos, bactérias e outros bichos que fazem mal. Manole. 2002;(2)193p.

10. Câmara SAV. Surtos de Toxinfecções Alimentares no Estado de Mato Grosso do Sul, no período de 19982001. Mato Grosso do Sul, 79 p. [Dissertação] (Monografia em Gestão em Saúde). Escola de Saúde Pública, Campo Grande/ MS, 2002.

11. Góes JAW. Consumo de Alimentos de Rua em Salvador: o que é que a baiana/(o) tem?. Bahia Análise e Dados. 1999;9(2):89-92.
12. Landgraf M. Microrganismos Indicadores. In: FRANCO BDGM, LANDGRAF, M. Microbiologia dos alimentos, São Paulo: Atheneu. 1996. p. 27-31.

13. Delú MAF, Sbampato CG, Mendonça AT, Iccoli RH, Maia SC. Avaliação microbiológica de cortes de frango resfriado, comercializados no município de Lavras, MG. Higiene Alimentar. 2006;20(138):83-85.

14. Cardoso ALSP, Castro AGM, Tessari ENC, Baldassi L, Pineiro ES. Pesquisa de Salmonella spp coliformes totais, coliformes fecais, mesófilos, em carcaças e cortes de frango. Higiene Alimentar. 2005;19(128):144-150.

15. Hagler NA, Hagler LCSM. Microbiologia sanitária. In: ROITMAN I, Travassos LR, Azevedo JL. (ed). Tratado de microbiologia. São Paulo: Manole; 1987. p. 186.

16. Bettega JMPR, et al. Métodos analíticos no controle microbiológico de água para consumo humano. Cienc. agrotec. [online]. 2006;30.

17. Cosby CM, Costello CA, Morris WC, Haughton B, Devereaux MJ, Harte F, Davidson PM. Microbiological Analysis of Food Contact Surfaces in Child Care Centers. Appl Environ Microbiol. 2008;74(22):6918-6922.

18. Brasil. Resolução RDC n 12, 2 de janeiro de 2001. Aprova o "Regulamento técnico sobre padrões microbiológicos para alimentos". Órgão emissor: ANVISA Agência Nacional de Vigilância Sanitária.

19. Oliveira TB, Maitan VB. Condições Higiênico Sanitárias de Ambulantes Manipuladores de Alimentos. Hig Alimente. 2010;6(9):1-14.

20. Souza GC, Santos CTD, Andrade AA, Alves L. Comida de rua: avaliação das condições higiênico-sanitárias de manipuladores de alimentos. Ciênc Saúde Coletiva. 2015;20(8):2329-2338. 